\title{
Immunofluorescent Detection and Quantification of Hepatitis A Virus Using Scanning Confocal Microscopy
}

\author{
I. Kukavica-Ibrulj ${ }^{*}$, A. Darveau ${ }^{* * *}$ and I. Fliss ${ }^{*}$ \\ * Centre de Recherche STELA, Département de Sciences des Aliments et de Nutrition, \\ Université Laval, Québec G1K 7P4 \\ ** Département de Biochimie et Microbiologie, Université Laval, Québec G1K 7P4
}

Human hepatitis A virus (HAV) is recognised as one of common cause of food and waterborne illnesses world-wide with high risk of morbidity and mortality.[1,2]. This virus is spread among humans by the fecal-oral route and many outbreaks have been commonly associated with waste water or food which are served raw or only lightly cooked, such as shellfish $[3,4,5,6]$, fruits and vegetables $[7,8]$. In nearly $50 \%$ of hepatitis A cases, the mode and vehicle(s) of virus spread remain unidentified. However several reports have suggested that infected human food handlers $[9,10]$ and/or use of contaminated water may play an important role in food and surface contamination.

In this study, an immunofluorescent method using anti-HAV polyclonal antibodies and confocal microscopy was developed to specifically detect HAV in waste water or attached to solid agri-food surfaces. The efficacy of the developed method was compared to that of the plaque assay and the flurorescent nucleic acid staining technique using SYBR Green II. The immunofluorescent method was shown to be very reliable for the detection of HAV attached on the four solid surfaces tested namely stainless steel, copper, polyethylene and polyvinyl chloride. It was also used for the specific and sensitive detection and quantification of HAV in waste water with a detection limit of $2 \times 10^{5}$ PFU. The viral counts estimated by the immunoflurescent technique were in correlation with those obtained by the nucleic acid labelling method using SYBR Green II and traditional plaque assay method.

In conclusion, the immunofluorescent method described hereby is rapid ( $3 \mathrm{~h})$ and sensitive and exhibits strong and very stable fluorescent signal. Therefore, it offers a powerful tool for qualitative and quantitative studies in both environmental and food sectors.

\section{References}

[1] R. S. Koff et al. 1998, Lancet 351:1643-1649

[2] J. S. Prevot et al.1993, Water Sci. Technol. 27:27-223

[3] J. C. A. Desenclos et al. 1991, Am. J. Public Health 81:1268-1272

[4] R. Enriquez et al. 1992, J. Med. Virol. 37:174-179

[5] F. Le Guyader et al. 1994, Appl. Environ. Microbiol. 60:3665-3671

[6] G. P. Richards et al. 1985, J. Food Prot. 48:815-823

[7] Centers for Diseases Control and Prevention, 1997, Morb. Mortal. Weekly Rep. 46:288-289

[8] Y. J. F. Hutin et al. 1999, N. Engl. J. Med. 340:595-602

[9] D. O. Cliver 1985, Public Health Rev. 13:235-292

[10] C. B Dalton, 1996, Arch. Intern. Med. 156:1013-1016 

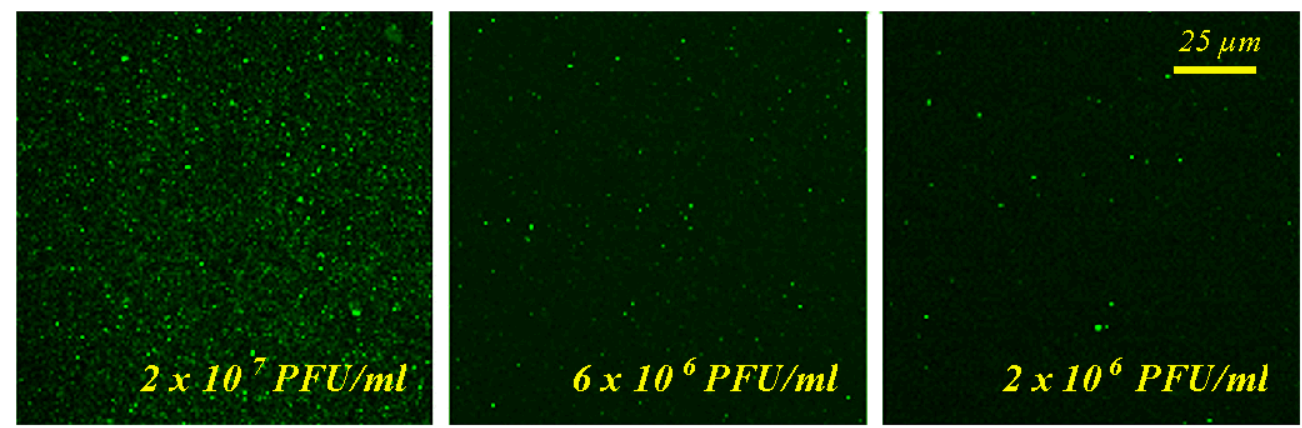

FIG. 1. Micrographs from confocal laser-scanning microscopy of three different concentrations of HAV using the immunofluorescent method.
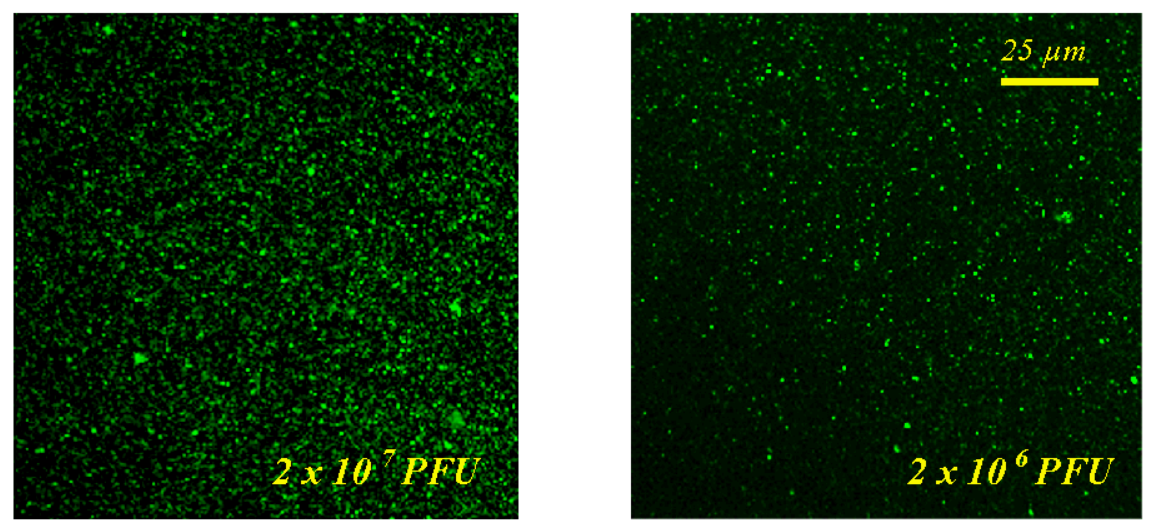

FIG. 2. Detection of HAV in experimentally spiked wastewater samples using the immunofluorescent method.

TABLE 1. Comparison of the viral counts obtained by the immunofluorescent method, fluorescent nucleic acid staining with SYBR Green II and traditional plaque assay

\begin{tabular}{crrrr}
\hline \multirow{2}{*}{ HAV } & \multicolumn{4}{c}{ Viral counts $\left(x 10^{5}\right.$ PFU of HAV/ml) } \\
\cline { 2 - 5 } & \multicolumn{1}{c}{ Plaque assay } & Immunofluorescence & \multicolumn{1}{c}{ SYBR Green II } \\
\hline Non diluted & $1175.00(35.35)^{\mathrm{a}}$ & $1327.80(486.17)$ & $1091.23(366.54)$ \\
$1 / 3$ & $497.50(3.54)$ & $578.34(87.44)$ & $616.67(241.71)$ \\
$1 / 5$ & $375.00(106.06)$ & $405.59(109.58)$ & $549.68(139.63)$ \\
$1 / 10$ & $172.50(74.25)$ & $199.41(96.71)$ & $244.72(83.06)$ \\
$1 / 33$ & $52.50(3.54)$ & $54.82(12.31)$ & $58.38(4.43)$ \\
$1 / 50$ & $45.00(7.07)$ & $44.09(12.61)$ & $42.08(13.69)$ \\
$1 / 100$ & $19.25(1.06)$ & $22.41(8.61)$ & $24.46(8.28)$ \\
$1 / 333$ & $5.25(0.35)$ & $5.79(0.54)$ & $7.18(2.22)$ \\
$1 / 500$ & $4.20(0.28)$ & $3.54(2.19)$ & $3.51(0.74)$ \\
$1 / 1000$ & $2.12(0.18)$ & $1.01(0.32)$ & $2.64(2.38)$ \\
\hline
\end{tabular}

a The values in parentheses are standard deviations based on the data obtained for at least 2 replicates 